\title{
Bathymetric segregation of spawning stages in the Atlantic sardine Sardina pilchardus
}

\author{
K. Ganias ${ }^{1, *}$, C. Nunes ${ }^{2}$ \\ ${ }^{1}$ Laboratory of Ichthyology, Department of Zoology, School of Biology, Aristotle University of Thessaloniki, \\ 54124 Thessaloniki, Greece \\ ${ }^{2}$ Instituto Nacional de Recursos Biological (INRB/IPIMAR), Avenida de Brasilia s/n, 1449-006 Lisboa, Portugal
}

\begin{abstract}
The present study analyzed the spatio-temporal pattern of spawning aggregations of the Atlantic sardine Sardina pilchardus using a large set of reproductive data derived from 5 daily egg production method (DEPM) surveys conducted off Portugal and the Gulf of Cadiz. Similar to previous results for the Mediterranean sardine, sardines in the Atlantic were shown to form ephemeral spawning aggregations in which actively spawning females separated spatially from the remaining population, taking with them a large proportion of males. These aggregations were shown to take place at depth; specifically, bathymetric positioning of reproductively active individuals changed during the spawning cycle in such a way that imminent spawners were located at greater depths compared to recent spawners or non-spawning females. This pattern of bathymetric segregation of sardine spawning stages is in agreement with previously published evidence that sardines spawn at depth, either from indirect acoustic sampling data or from the occurrence of early embryonic stages at greater depths. A number of physiological mechanisms that may explain changes in the bathymetric positioning of actively spawning individuals are also suggested.
\end{abstract}

KEY WORDS: Spawning aggregations - Reproductive behavior - Spawning frequency · Sardine • Atlantic

\section{INTRODUCTION}

Sardina pilchardus is a short-living temperate clupeoid adapted to a pelagic lifestyle. It exhibits schooling behavior even in pre-recruit stages (Smith et al. 2001) and its schools utilize the pelagic environment for feeding, protection, and reproduction through extended seasonal/horizontal (Morello \& Arneri 2009) and vertical/diurnal (Giannoulaki et al. 1999, Zwolinski et al. 2006) migrations.

Sardines release multiple batches of pelagic eggs (Ganias et al. 2004) through protracted spawning periods in which duration and timing display both latitudinal (Stratoudakis et al. 2006) and size-related (Silva et al. 2006, Ganias et al. 2007) shifts. During the spawning season, population egg production is continuous, and each day a relatively small fraction $(\sim 10 \%$; Ganias et al. 2003) of the reproductively active population is reproducing, suggesting that at any given time active individuals are in various spawning states. On the other hand, diurnal spawning activity in imminent spawners is highly synchronized (Ganias et al. 2011), with peak spawning taking place at night $\left(\sim 21: 00 \mathrm{~h}_{\text {; }}\right.$ Bernal et al. 2001).

Night spawning behavior in Sardina pilchardus is accompanied by the formation of ephemeral spawning aggregations: actively spawning females separate from the remaining population, taking with them a large proportion of males (Ganias et al. 2003, Ganias 2008). Such aggregations are identified by hauls with increased proportions of actively spawning females and skewed sex ratios (Ganias et al. 2003) and may also be prominent in anchovy populations (Hunter \& Goldberg 1980, Alheit 1985). Based on the classifica- 
tion of Domeier \& Colin (1997), such formations belong to the resident type of spawning aggregations, which draw individuals from local areas and last only a few hours at specific times of the day, and the daily egg production represents only a fraction of the population's annual egg production. The same authors also suggested that resident spawning aggregations are formed by small to medium-sized species that feed low in the trophic chain, which is the case for sardines and other multiple spawning clupeoids. Indeed, Ganias (2008) gathered information for several sardine and anchovy stocks worldwide and showed that ephemeral spawning aggregations is a more generalized characteristic in multiple spawning clupeoids.

Irrespective of the exact criteria that adult sardines use to segregate from the remaining population and to select their spawning sites, bathymetric segregation and spawning at depth provides a reasonable explanation for the occurrence of unfertilized and newly fertilized eggs at greater depths for many sardine populations (Australian sardine Sardinops sagax: Fletcher \& Summer 1999; Japanese sardine Sardinops melanostictus: Matsuoka \& Konishi 1996; South African sardine Sardinops sagax: Dopolo et al. 2005). These studies provide evidence that sardine spawning occurs in deeper water layers, since unfertilized eggs and very early egg stages were mostly prevalent at 40 to $60 \mathrm{~m}$ depth. Zwolinski et al. (2006) showed an offshore distribution for Sardina pilchardus eggs in the North Atlantic, with Day 0 and Day 1 cohorts occurring between 50 and $80 \mathrm{~m}$ bottom depth. The same authors found, using acoustic sampling, that the mature sardines that contributed to the spawning of these egg cohorts were located at $60 \mathrm{~m}$ depth. Zwolinski et al. (2007) suggested that large shoals of actively spawning sardines are formed in close association to the seabed around the hours of spawning.

Despite the accumulated evidence on the spawning depth of various sardine populations, the exact spatiotemporal arrangement of actively spawning individuals has never been assessed in the field and the question of whether ephemeral spawning aggregations both in sardine and other clupeoids take place with depth still remains undetermined. The purpose of the present study was to analyze the spatio-temporal pattern of spawning aggregations in the Atlantic sardine Sardina pilchardus. We used a large collection of reproductive data from the sardine's peak spawning season derived from 5 daily egg production method (DEPM) surveys conducted off Portugal and the Gulf of Cadiz. DEPM surveys provide a unique means of assessing spawning dynamics in fish populations because large numbers of histological data on the spawning state of individuals can be directly related to several spatio-temporal variables, such as sampling time, location, and depth. In addition, we tested a physiological mechanism that could explain changes in the bathymetric positioning of actively spawning females based on the relationship between gonadal state and swimbladder dynamics.

\section{MATERIALS AND METHODS}

Adult sardines were sampled off Portugal and the Gulf of Cadiz within the remit of 5 DEPM surveys done in 1997, 1999, 2002, 2005, and 2008 for the estimation of the spawning biomass of Atlanto-Iberian sardine stock (Table 1). Samples were collected during sardine peak spawning months (January to March) either on board the RVs 'Noruega' (in 1997, 1999, 2002, and 2008) and 'Capricórnio' (in 2005) and/or from the commercial purse-seine fleet. For each fishing set, information on position, bottom depth, and time of capture was available, while for RV samples, hauling depth was also recorded. Sampling with the 2 RVs was performed using either a pelagic trawl (vertical opening of 8 to $9 \mathrm{~m}$, cod-end mesh size of $20 \mathrm{~mm}$, operated at 3.5 to 4 knots) or a bottom trawl (vertical opening of $3.5 \mathrm{~m}$, cod-end mesh size of $20 \mathrm{~mm}$, operated at 3.5 knots). Bottom depth in RVs was obtained from the scientific acoustic sounder SIMRAD EK500, while haul depth was determined using a SCANMAR trawl-eye sounder. Sardine schools have an average height of 3 to $4 \mathrm{~m}$ and are usually fished close to the bottom (up to $10 \mathrm{~m}$ above the bottom), due to a strong down-dive reaction to the fishing boat ( $\mathrm{V}$. Marques, IPIMAR, pers. comm.), which was confirmed by the strong relationship between fishing depth and bottom depth (Fig. 1).

Samples consisted of a random collection of 2.5 to $5 \mathrm{~kg}$ of sardines, making a total of 50 to 100 ind. sam$\mathrm{ple}^{-1}$. Fish were sexed immediately after capture,

Table 1. Sardina pilchardus. Number of hauls and number of male $\left(\mathrm{n}_{\mathrm{m}}\right)$ and female $\left(\mathrm{n}_{\mathrm{f}}\right)$ sardines used in each daily egg production method (DEPM) survey. $\mathrm{n}_{\mathrm{fh}}$ : number of females processed histologically; $L$ : body length

\begin{tabular}{|ccccrrr|}
\hline Year & $\begin{array}{c}\text { Date range } \\
\text { (dd/mm) }\end{array}$ & $\begin{array}{c}\text { No. of } \\
\text { hauls }\end{array}$ & $\mathrm{n}_{\mathrm{m}}$ & $\mathrm{n}_{\mathrm{f}}$ & $\mathrm{n}_{\mathrm{fh}}$ & \multicolumn{1}{c}{$\begin{array}{c}L \text { mean } \pm \mathrm{SD} \\
\text { (cm) }\end{array}$} \\
\hline 1997 & $6 / 3$ to $24 / 3$ & 40 & 528 & 772 & 245 & $18.2 \pm 2.1$ \\
1999 & $1 / 1$ to $5 / 2$ & 39 & 1608 & 2190 & 374 & $17.3 \pm 2.5$ \\
2002 & $9 / 1$ to $17 / 2$ & 76 & 2056 & 2916 & 202 & $16.8 \pm 3.0$ \\
2005 & $17 / 1$ to $25 / 2$ & 66 & 2082 & 2385 & 1458 & $17.2 \pm 3.4$ \\
2008 & $21 / 1$ to $17 / 2$ & 85 & 2181 & 2621 & 1872 & $19.2 \pm 2.3$ \\
\hline
\end{tabular}




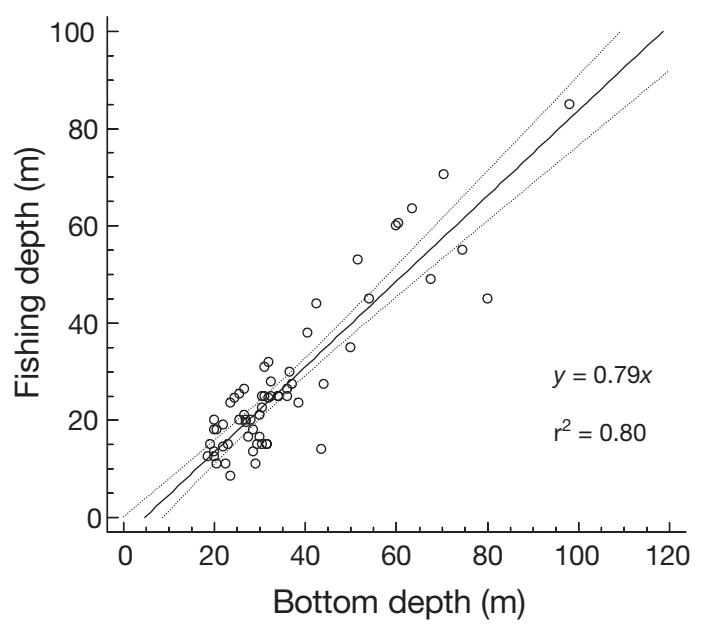

Fig. 1. Relationship between bottom depth and fishing depth for the daily egg production method (DEPM) hauls collected by 2 research vessels. The regression intercept was not significant $(\mathrm{p}>0.1)$ and the equation was forced through zero. The regression line (solid line) and its 95\% CI (dotted lines) are shown

scored macroscopically for maturity and fat content, and measured for total length $(L$; to the nearest $0.1 \mathrm{~cm}$ ) and gutted weight $\left(W_{i}\right.$ to the nearest $0.1 \mathrm{~g}$ ). Sex ratio $(S R)$ was the numeric fraction of females in each sample. Macroscopic maturity in both males and females was determined using a 5-stage key: I, immature; II, developing; III, spawning-capable; IV, spawning (hydration stage for females); and $\mathrm{V}$, regressing (Afonso-Dias et al. 2007). Subsequently, ovaries were placed in jars with formalin or alcohol, formalin, and acetic acid (AFA) solution and transferred to the laboratory for further analysis. A total of 19939 sardines were used for the analysis (Table 1).

In the laboratory, $24 \pm 6.7$ (SD) females from each sample were dissected and their ovaries were dried of surface moisture and weighed (to the nearest $0.01 \mathrm{~g}$ ). A small part of ovarian tissue was dehydrated, cleared in xylol, embedded either in paraffin $(1997,2002,2005$, and 2008 samples) or resin (1999 samples) and histological sections were cut at $5 \mu \mathrm{m}$ (paraffin) or $3 \mu \mathrm{m}$ (resin). Scoring of histological preparations included the developmental stage of the advanced group of oocytes, the presence and histological characteristics of postovulatory follicles (POFs), and the prevalence and intensity of different stages of atretic follicles. POFs consist of the follicular layers that remain in the ovary after the release of the ovum during spawning and constitute the most reliable evidence of previous spawning activity in fish. When POFs were detected, slides were scanned in detail to locate the largest POF, which was photographed and measured at its crosssectional area (Ganias et al. 2007). Subsequently, using criteria developed by Ganias et al. (2004) for the Mediterranean sardine, females were classified as reproductively active or inactive, the former displaying at least one batch of healthy vitellogenic oocytes. Active females were further classified as spawning or non-spawning, the former showing evidence of imminent (undergoing germinal vesicle breakdown [GVBD] or oocyte hydration) and/or recent (having POFs) spawning activity.

Spawning lag $\left(t_{\mathrm{s}}\right)$ was the time lag before or after the spawning act in imminent and recent spawners respectively. GVBD in sardines begins during the first morning hours of the day of spawning (Ganias et al. 2011). In that respect, $t_{\mathrm{s}}$ in imminent spawners was estimated as the time lag between the time of capture and the average daily spawning time (dst) for the Iberian sardine (21:00 h; Bernal et al. 2001). Even if spawning is supposed to be distributed normally around $d s t$ (Bernal et al. 2001), in our samples hydrated females were only prominent between noon and $d s t$; this was probably due to reduced sampling effort between 21:00 $\mathrm{h}$ and the first morning hours. In that respect, no adjustments were needed to the $t_{\mathrm{s}}$ of hydrated females caught after $d s t$. For recent spawners, $t_{\mathrm{s}}$ was estimated after aging their POFs using procedures described in Ganias et al. (2007). Specifically, $t_{\mathrm{s}}$ was estimated by fitting POF cross-sectional areas to a fixed POF area versus age curve and by validating the estimated age using a histomorphological POF aging key (Ganias et al. 2007). The $t_{\mathrm{s}}$ of recent spawners with very early POFs caught a few hours before $d s t$ was set to zero; however, the fraction of these fish was particularly low. Based on this procedure, female spawners were assigned to 1 of 5 daily cohorts, 1 for imminent spawners $\left(\right.$ Day $_{-1}$ ) and 4 for recent spawners (Day, Day, Day $_{2}$, and $\left.\mathrm{Day}_{3}\right)$.

Principal component analysis (PCA) was used to study the ordination pattern of DEPM hauls in the data matrix $X_{H \times S}$, where $H$ (rows) is the number of hauls and $S$ (columns) is the 5 daily spawners' cohorts plus non-spawning females. Immature females were excluded from the analysis. If present, intrinsic patterns in the multidimensional swarm of different spawning classes would emerge within a plot of the first 2 or 3 components. A component was considered to explain a significant proportion of the variance in the multidimensional data set when its associated eigenvalue was $>1.0$.

Bathymetric trends with spawning stage were analyzed using both macroscopic and histological maturity data. The sampling bottom depths for the 5 macroscopic maturity stages were compared in both sexes using the Kruskal-Wallis test. Data from the histological survey were used to study the spatio-temporal pattern of spawning aggregations in more detail. To do so, 
the fraction of the $i$ th daily spawning class in the $h$ th haul $\left(S_{i h}\right)$, the spawning lag $\left(t_{\mathrm{s}}\right)$, and bottom depth $(d)$ were treated as a 3-dimensional XYZ data matrix where $t_{\mathrm{s}}$ and $d$ represented XY coordinates. A distance-weighted least-squares (DWLS) smoothing procedure of quadratic polynomial order was subsequently used to interpolate and visualize the spatio-temporal distribution of $S_{\text {ih }}$ into a 3D surface plot. DWLS differs from other smoothing procedures in that the influence of individual points decreases with the horizontal distance from the respective points on the surface. These results together with results from the PCA were used to visually examine the exact pattern by which actively spawning females segregate from the remaining population.

\section{RESULTS}

Both male and female sardines were shown to segregate with respect to their reproductive stage. Macroscopic maturity data showed that the depth of occurrence of Stage IV (spawning) sardines, both males and females, was significantly greater compared to both Stage III (spawning-capable) sardines and those at the remaining maturity stages (Fig. 2; Kruskal-Wallis test for both males and females: $\mathrm{p}<0.001$ ).

We investigated bathymetric segregation in relation to spawning state in more detail using data from the histological surveys. The first step was to analyze the

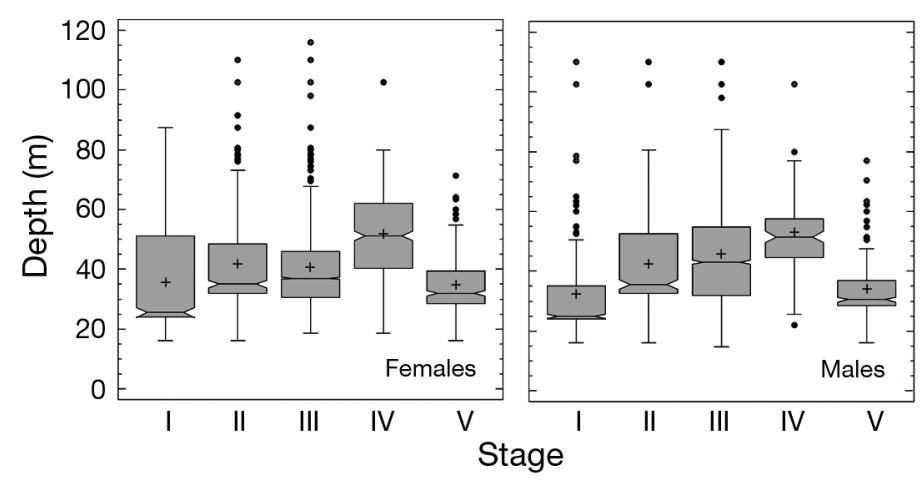

Fig. 2. Sardina pilchardus. Boxplots of bottom depth vs. maturity stage showing the mean $(+)$, the median notch and the outliers for females and males. I: immature, II: developing, III: spawning-capable, IV: spawning, V: regressing spatial segregation of imminent spawners by means of PCA through the ordination of DEPM hauls in the multi-dimensional swarm of different daily spawning classes (Fig. 3). PCA resulted in 3 significant principal components, which explained $78.3 \%$ of variability in $X_{H \times S}$ (Table 2). Visual inspection of the 2-dimensional plot of component weights indicated that each of the first 2 principal components was related to a different ordination pattern (Fig. 3). Catches on the first principal component (PC-I) were ordinated based on the incidence of spawning activity (either preceding or imminent), since daily spawning classes were positively correlated to each other and negatively to nonspawning females (Fig. 3). PC-I scores did not correlate significantly with bottom depth (Pearson correlation coefficient: $-0.13 ; p>0.1$ ), indicating that this segregation of non-spawning females from imminent and recent spawners is not bathymetric. Most probably, ordination along PC-I reflects the geographic variability of the spawners' fractions, e.g. due to environmental variability. However, further exploration of this pattern was outside the scope of the present work.

The second principal component (PC-II) was shown to separate catches based on the proportion of females 

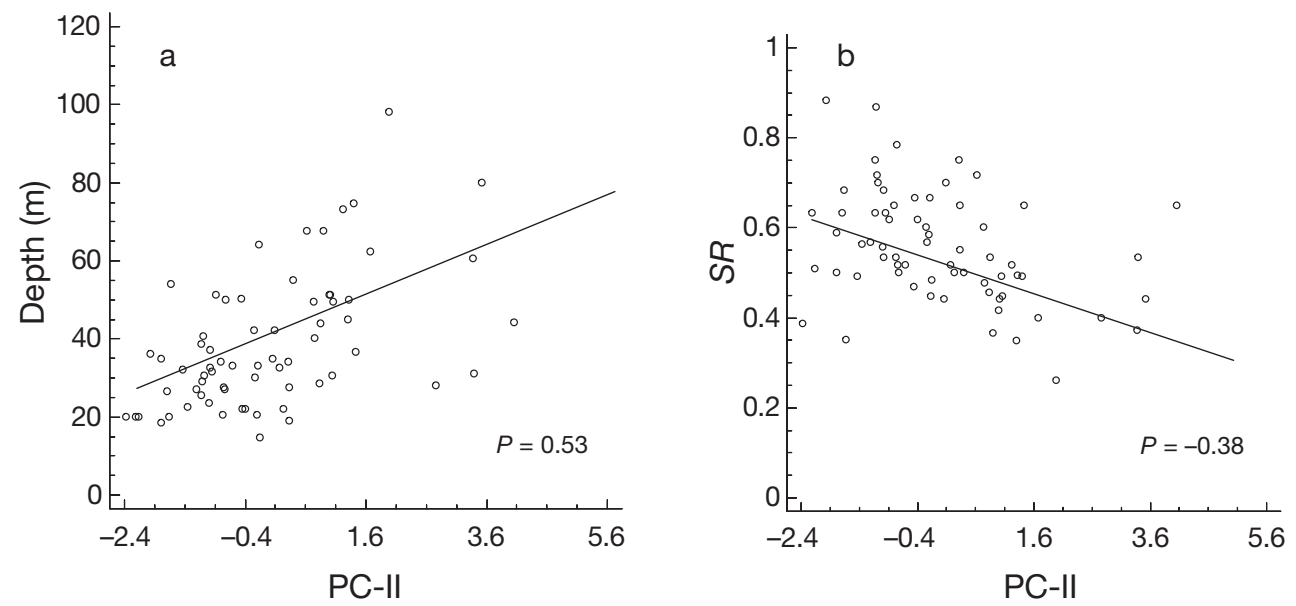

Fig. 4. Sardina pilchardus. Relationship between the second principal component (PC-II) and (a) bottom depth and (b) sex ratio $(S R$, indicating the fraction of females in each haul) for the 2008 DEPM survey. P: Pearson correlation coefficient. The linear regression trendline is superimposed on both graphs

to each Day, class. Specifically, Day-1 females were negatively correlated to all Day ${ }_{1+}$ classes, while Day females were at an intermediate position along PC-II (Table 2, Fig. 3). PC-II scores correlated positively with bottom depth (Pearson correlation coefficient: 0.25, p < 0.05), indicating that spatial segregation takes place with depth, which is in accordance with results from the macroscopic maturity data. Moreover, PC-II scores were negatively correlated with sex ratio (Pearson correlation coefficient: $-0.37, \mathrm{p}<0.01$ ), suggesting that Day $_{-1}$ females segregate with depth, taking with them a large proportion of males. This pattern was particularly prominent in 2008, when PC-II exhibited a strong correlation with bottom depth (Fig. 4a), while the correlation with sex ratio was similar to that from the analysis for all study years (Fig. 4b). As shown in Fig. 5, the 2008 survey was exceptionally good for studying spawning aggregations, as the number of hauls with increased (>25\%) fractions of Day ${ }_{-1}$ females was quite high.

The exact spatio-temporal pattern of the segregation of sardine spawning stages was studied using a 3D DWLS plot (Fig. 6). According to this plot, actively

Table 2. Sardina pilchardus. Eigenvalues, percent of variance, and component weights for the 5 daily spawning classes and non-spawning active females (nsf) for significant principal components from the standardized principal component analysis

\begin{tabular}{|c|c|c|c|c|c|c|c|c|}
\hline \multirow{2}{*}{$\begin{array}{l}\text { Principal } \\
\text { component }\end{array}$} & \multirow{2}{*}{$\begin{array}{l}\text { Eigen- } \\
\text { value }\end{array}$} & \multirow{2}{*}{$\begin{array}{c}\% \\
\text { variance }\end{array}$} & \multicolumn{6}{|c|}{ Component weights } \\
\hline & & & Day $_{-1}$ & Day $_{0}$ & Day $_{1}$ & $\mathrm{Day}_{2}$ & $\mathrm{Day}_{3}$ & $\mathrm{nsf}$ \\
\hline PC-I & 2.01 & 33.46 & -0.11 & -0.32 & -0.48 & -0.42 & -0.34 & 0.61 \\
\hline PC-II & 1.66 & 27.59 & 0.67 & 0.23 & -0.11 & -0.41 & -0.43 & -0.36 \\
\hline PC-III & 1.04 & 17.33 & 0.47 & -0.72 & -0.25 & 0.16 & 0.39 & -0.17 \\
\hline
\end{tabular}

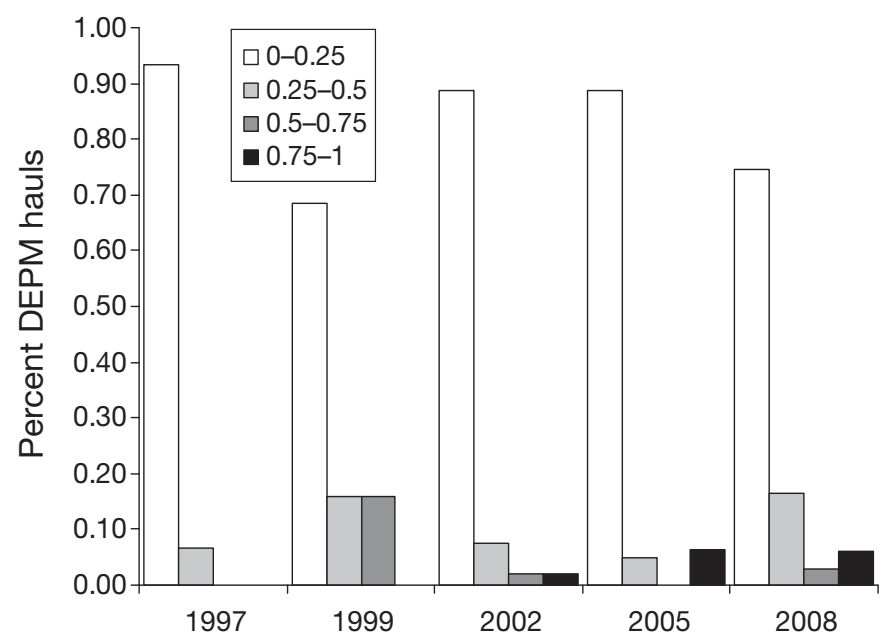

Fig. 5. Sardina pilchardus. Frequency distribution of daily egg production method (DEPM) hauls based on the proportion of imminent spawners (4 classes exemplified in the key) for each of the $5 \mathrm{yr}$ of study

spawning females occurred at greater depths before, during, and a few hours after mean dst. This result indicates that not only imminent spawners but also very recent spawners are segregated spatially from the remaining spawning classes, which also explains the intermediate position of the Day class along PC-I. Late Dayo spawners move to lower depths a few hours after $d s t$, and this depth of occurrence remains almost unchanged until the following spawning. 


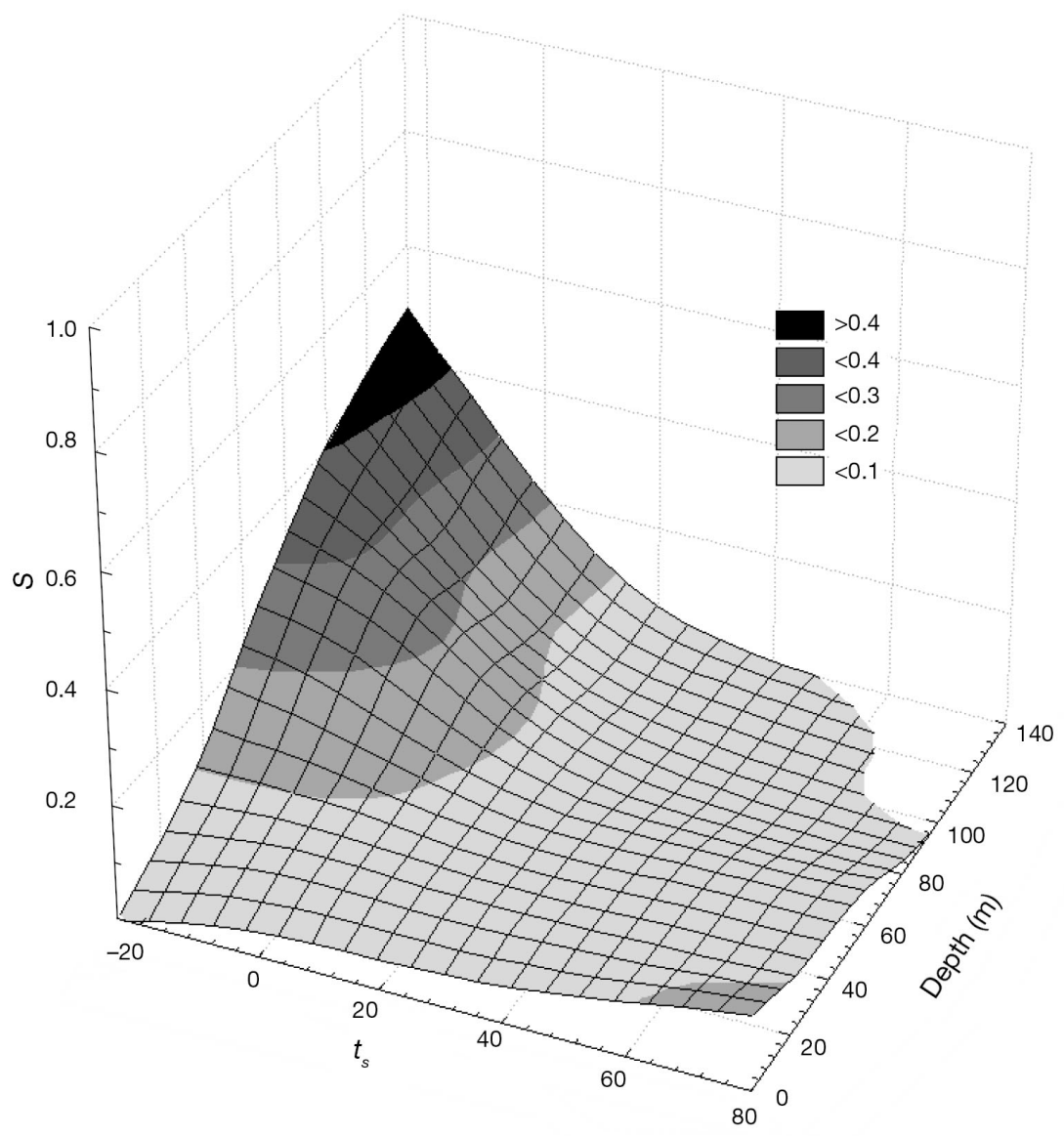

Fig. 6. Sardina pilchardus. Distance-weighted least-squares plot illustrating the effect of capture depth $(\mathrm{m})$ and spawning lag $\left(t_{\mathrm{s}}, \mathrm{h}\right)$ on spawning fraction $(S)$. The key shows 5 classes of $S$ value

that segregation of spawning stages takes place on the horizontal plane, with spawning individuals moving offshore to spawn. However, since bottom depth was strongly related to fishing depth, at least for samples from the 2 research vessels, this segregation could additionally take place on a vertical plane, with spawning individuals also moving downwards to spawn. The latter is in agreement with reports for several sardine populations that unfertilized eggs or very early egg stages occur at 40 to $60 \mathrm{~m}$ depth (Matsuoka \& Konishi 1996, Fletcher \& Summer 1999, Dopolo et al. 2005).

To our knowledge, this is the first detailed report of bathymetric segregation of spawning stages both in multiple spawning clupeoids and in pelagic marine teleosts in general. Schabetsberger et al. (1999) suggested that walley pollock Theragra chalcogramma also spawn at deeper layers in male-biased spawning aggregations; however, their hypothesis was based on indirect evidence, i.e. sexual differences in the intensity of egg cannibalism: males spent more time at depths of higher egg densities, indicating a pattern of bathymetric stratification of spawning stages and sex ratio. Mowbray (2002) found that

\section{DISCUSSION}

The present work shows that, similar to the Mediterranean sardine population (Ganias et al. 2003, Ganias 2008), the Atlantic sardine forms ephemeral spawning aggregations in such a way that actively spawning females segregate from the remaining population, taking with them a large proportion of males. Formulation of spawning aggregations is quite common in marine fish; in many populations, spawning individuals are spatially separated from their conspecifics to form spawning groups. Group spawning behavior allows synchrony in the timing of gamete production, optimizes fertilization rates and survival rates of the offspring, and helps regulate the sex ratio in some populations. On the other hand, haphazard release of gametes could result in a high proportion of eggs going unfertilized (Claydon 2005).

The present work adds to the evidence that segregation of actively spawning individuals, both females and males, takes place with depth. Since bathymetric trends are based on bottom depth, our results imply for capelin Mallotus villosus, the proportion of sexually mature fish was positively correlated with fishing depth, although the explanatory power of the relationship was weak. In contrast to the sardine, capelin deposits demersal eggs, and vertical segregation with respect to spawning state is predicted by its reproductive life history (Davoren et al. 2006).

For herring Clupea harrengus, Johnsen \& Skaret (2008) documented that persistent vertical hourglass formations occurred during the critical spawning period, and the proportion of spawners to pre- and post-spawners was significantly higher in the lower than in the upper component of these formations. However, similar to capelin, herring are substrate spawners, and the occurrence of demersal spawning schools that segregate from the remaining, nonspawning fish would be expected. Similar results for herring by Stratoudakis et al. (1998) showed that spawning over a single multi-layer egg mat progressed within at least $2 \mathrm{wk}$, with consecutive groups of fish getting to the bottom, depositing eggs, and leaving. 
The most important physiological mechanisms controlling buoyancy and bathymetric positioning in teleosts are somatic fat deposition, tissue-density control, and swimbladder dynamics (Brix et al. 2009). Among these mechanisms, fat deposition should be excluded as a trigger of bathymetric segregation at spawning because fat cycling in sardines occurs on a seasonal basis (Nunes et al. 2011a) while spawning cycling occurs several times within the breeding season (Nunes et al. in 2011b). However, the remaining 2 mechanisms, i.e. changes in swimbladder dynamics and body-tissue density, could be partially linked to changes in the vertical positioning of actively spawning individuals. Even though the relationship between swimbladder dynamics and reproductive state has not been widely explored, it has been documented for a few fish species, e.g. Japanese eel Anguilla japonica (Yamada et al. 2004). Furthermore, Ona (1990) found for several fish species that changes in swimbladder volume are inversely related to changes in the size of various visceral organs, including the gonads. Thus, for fish in which the swimbladder serves as a hydrostatic organ and changes in the size of visceral organs may affect swimbladder volume, an abrupt increase in the size of an organ, e.g. gonads, would cause shrinkage of the swimbladder and sinking of the individuals.

This phenomenon might be more pronounced for physostomous species such as clupeoids, i.e. fish whose swimbladder is connected at some point to the digestive tract by 1 or 2 open ducts, which makes it more sensitive to losing air. Blaxter \& Batty (1984) observed that herrings with full stomachs and welldeveloped gonads generally have deflated swimbladders, which according to Whitehead \& Blaxter (1989) could be an immediate physiological constraint to the buoyancy function. Such a physiological mechanism, predicting deflation of the swimbladder and negative buoyancy due to organ competition in the finite body cavity, might partially explain bathymetric segregation of actively spawning sardines, because sardine ovaries undergo an abrupt increase in size in imminent spawners due to hydration (Somarakis et al. 2004). Indeed, using on-board information from acoustic surveys, we found that swimbladder size was related to spawning state (see Appendix 1 for more details). Specifically, hydrated females mainly possessed swimbladders of small or medium size, while none of the females with a distended swimbladder was hydrated (Fig. 7).

Differential bathymetric positioning might additionally or alternatively be explained in terms of spawning-related differences in swimming performance and locomotion. Although constraints on locomotion have been suggested in gravid females of many animal species (for review see Magnhagen 1991), the effect of pregnancy on locomotion has rarely been measured in
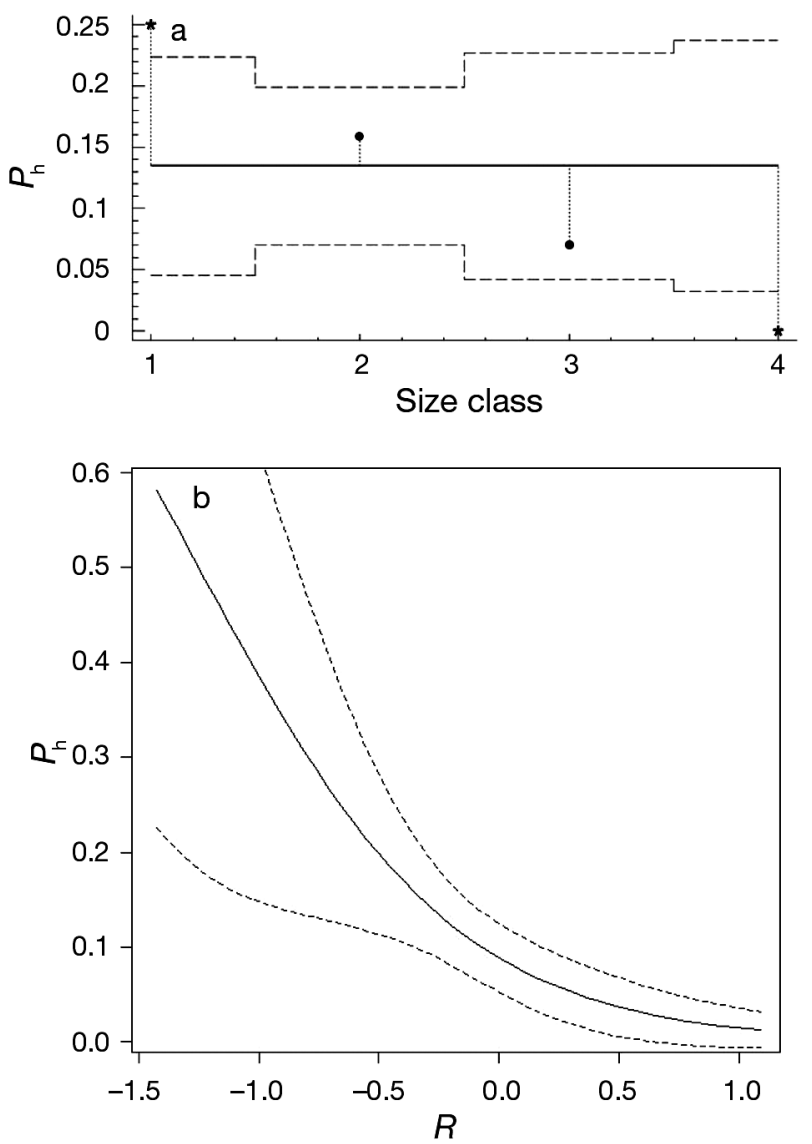

Fig. 7. Sardina pilchardus. (a) Analysis of means (ANOM) plot comparing the prevalence of hydrated females $\left(P_{\mathrm{h}}\right)$ between swimbladder size classes. Vertical bars represent the difference between $P_{\mathrm{h}}$ values and the grand mean (horizontal solid line). $95 \%$ decision limits are shown (dashed horizontal lines). * Significantly different from the grand mean. (b) Fitted model for the relationship between $P_{\mathrm{h}}$ and the residuals $(R)$ of the swimbladder cross-section vs. body length relationship. $95 \%$ CI of the model line is shown (dashed lines)

fish (James \& Johnston 1998, Plaut 2002). In these 2 studies, gravid fish displayed decreased swimming performance, which was mainly attributed to the added mass of eggs; the latter might either cause hydrodynamic or biomechanical constraints or decrease the amount of oxygen that can be allocated to swimming (Plaut 2002). Indeed, as mentioned in the previous paragraph (see also Somarakis et al. 2004), the process of hydration adds a significant amount of mass in imminent spawners, since the gonadosomatic index increases within a few hours from $5 \%$ at the completion of yolk deposition to $>20 \%$ at the final stages of hydration (Somarakis et al. 2004). Considering that the increase in ovarian volume at hydration is counterbalanced by the deflation of the swimbladder, then the volume of the coelomic cavity and thus whole body volume should remain unaffected. In that respect, 
hydration would be expected to increase the specific gravity of the body and thus individuals would be more susceptible to sinking, a pattern which also predicts bathymetric segregation between different spawning stages.

The effect of ovarian hydration on swimbladder dynamics and specific gravity may only explain the movement or the retention of imminent spawners at lower depths. However, as also shown for the Mediterranean sardine by Ganias et al. (2003), very recent spawners in the present study, i.e. early Dayo females, are also segregated spatially. In addition, the occurrence of spawning males at greater depths may not be explained by the effect of hydration. In that respect, the aforementioned physiological mechanisms may only provide a partial explanation for the spawning-related bathymetric distribution of each individual separately. However, when such mechanisms are considered alone without taking into account the sum of mechanistic models for how fish sense and respond to their surroundings (reviewed by Giske et al. 1998), they prove inadequate for explaining fish aggregating behavior, including the formation of ephemeral spawning aggregations. Such formations presuppose collective behavior patterns that are mainly based on the interactions of individuals, which in turn depend on a complex sum of sensory stimuli (Weissburg \& Browman 2005). Such collective behavior during spawning was shown by means of egg and acoustic sampling data for the Atlantic sardine stock by Zwolinski et al. (2006, 2007). Therefore, even if buoyancy is affected by pregnancy and spawning individuals are forced to move offshore and downwards to spawn, the formation of massive and functional social structures that ensure spawning success through enhancing fertilization rates and progeny survival would also require intra- and intersexual interaction among individuals.

Acknowledgements. This work was supported by the National Sampling Plan for DEPM surveys funded by the European Union. Thanks are due to Y. Stratoudakis, A. Silva, and V. Marques for helpful recommendations. S. Michou is thanked for contributing to the measurement of swimbladder cross-sections. Particular thanks are due to all IPIMAR staff who contributed to the collection of DEPM samples and the histological preparations. Three anonymous referees are also thanked for their comments, which improved the quality of the manuscript.

\section{LITERATURE CITED}

Afonso-Dias I, Amorim P, Silva A (2007) Problems with assigning the ovaries of sardine (Sardina pilchardus) to the appropriate macroscopic maturity stage. JMBA Biodiversity Records No. 5190. Marine Biological Association UK, Plymouth. Available at: www.mba.ac.uk/jmba/ biodiversityrecords.php
Alheit J (1985) Spawning frequency of Peruvian anchovies taken with a purse seine. In: Lasker R (ed) An egg production method for estimating spawning biomass of pelagic fish: application to the northern anchovy, Engraulis mordax. NOAA Tech Rep NMFS 36. NOAA Fisheries Service, Silver Spring, MD, p 59-61. Available at: http://spo.nwr. noaa.gov/trlist.htm

Bernal M, Borchers D, Valdes L, Lago de Lanzos A, Buckland ST (2001) A new ageing method for eggs of fish species with daily spawning synchronicity. Can J Fish Aquat Sci 58:2330-2340

Blaxter JHS, Batty RS (1984) The herring swimbladder: loss and gain of gas. J Mar Biol Assoc UK 64:441-459

Brix O, Gruner R, Ronnestad I, Gemblalla S (2009) Whether depositing fat or losing weight, fish maintain a balance. Proc R Soc B 276:3777-3782

Claydon J (2005) Spawning aggregations of coral reef fishes: characteristics, hypotheses, threats and management. Oceanogr Mar Biol Annu Rev 42:265-301

> Davoren GK, Anderson JT, Montevecchi WA (2006) Shoal behaviour and maturity relations of spawning capelin (Mallotus villosus) off Newfoundland: demersal spawning and diel vertical movement patterns. Can J Fish Aquat Sci 63:268-284

Domeier ML, Colin PL (1997) Tropical reef fish spawning aggregations: defined and reviewed. Bull Mar Sci 60: 698-726

Dopolo MT, van der Lingen CD, Moloney CL (2005) Stagedependent vertical distribution of pelagic fish eggs on the western Agulhas Bank, South Africa. Afr J Mar Sci 27: $249-256$

> Fletcher WJ, Summer NR (1999) Spatial distribution of sardine (Sardinops sagax) eggs and larvae: an application of geostatistics and resampling to survey data. Can J Fish Aquat Sci 56:907-914

> Ganias K (2008) Ephemeral spawning aggregations in the Mediterranean sardine, Sardina pilchardus: a comparison with other multiple-spawning clupeoids. Mar Biol 155: 293-301

Ganias K, Somarakis S, Machias A, Theodorou A (2003) Evaluation of spawning frequency in a Mediterranean sardine population (Sardina pilchardus sardina). Mar Biol 142: 1169-1179

Ganias K, Somarakis S, Machias A, Koutsikopoulos C, Theodorou A (2004) Identifying newly spawned female sardines by means of common fisheries data. Cybium 28:43-46

> Ganias K, Somarakis S, Koutsikopoulos C, Machias A (2007) Factors affecting the spawning period of sardine in two highly oligotrophic seas. Mar Biol 151:1559-1569

Ganias K, Nunes C, Rakka M, Vavalidis T, Stratoudakis Y (2011) Estimating oocyte growth rate and its potential relationship to spawning frequency in teleosts with indeterminate fecundity. Mar Coast Fish (in press)

- Giannoulaki M, Machias A, Tsimenidis N (1999) Ambient luminance and vertical migration of sardine Sardina pilchardus. Mar Ecol Prog Ser 178:29-38

> Giske J, Huse G, Fiksen O (1998) Modelling spatial dynamics of fish. Rev Fish Biol Fish 8:57-91

Hunter JR, Goldberg SR (1980) Spawning incidence and batch fecundity in northern anchovy, Engraulis mordax. Fish Bull 77:641-652

James RS, Johnston IA (1998) Influence of spawning on swimming performance and muscle contractile properties in the short-horn sculpin. J Fish Biol 53:485-501

Johnsen E, Skaret G (2008) Adaptive mass formations in fish shoals founded in conflicting motivation. Mar Ecol Prog Ser 358:295-300 
Magnhagen C (1991) Predation risk as a cost of reproduction. Trends Ecol Evol 6:183-186

Matsuoka M, Konishi Y (1996) Morphological characteristics of unfertilized eggs of the Japanese sardine, compared with fertilized ones. Fish Sci 62:855-859

Morello EB, Arneri E (2009) Anchovy and sardine in the Adriatic Sea - an ecological review. Oceanogr Mar Biol Annu Rev 47:209-255

Mowbray FK (2002) Changes in the vertical distribution of capelin (Mallotus villosus) off Newfoundland. ICES J Mar Sci 59:942-949

Nunes C, Silva A, Soares E, Ganias K (2011a) The use of hepatic and somatic indices and histological information to characterize the reproductive dynamics of sardine from the Portuguese coast. Mar Coast Fish (in press)

Nunes C, Marques V, Silva A, Ganias K (2011b) Integrating fish size, condition and population demography on the estimation of sardine annual fecundity. Cienc Mar (in press)

Ona E (1990) Physiological factors causing natural variations in acoustic target strength of fish. J Mar Biol Assoc UK 70: $107-127$

Plaut I (2002) Does pregnancy affect swimming performance of female mosquitofish, Gambusia affinis? Funct Ecol 16:290-295

Schabetsberger R, Brodeur RD, Honkalehto T, Mier KL (1999) Sex-biased egg cannibalism in spawning walleye pollock: the role of reproductive behavior. Environ Biol Fishes 54: 175-190

Silva A, Santos M, Caneco B, Pestana G, Porteiro C, Carrera P, Stratoudakis Y (2006) Temporal and geographic variability of sardine maturity at length in the northeastern
Atlantic and the western Mediterranean. ICES J Mar Sci 63:663-676

Smith PE, Horne JK, Schneider DC (2001) Spatial dynamics of anchovy, sardine, and hake pre-recruit stages in the California Current. ICES J Mar Sci 58:1063-1071

Somarakis S, Ganias K, Tserpes G, Koutsikopoulos C (2004) On gonadal allometry and the use of the gonosomatic index: a case study in the Mediterranean sardine, Sardina pilchardus. Mar Biol 146:181-189

Stratoudakis Y, Gallego A, Morrison JA (1998) Spatial distribution of developmental egg ages within a herring Clupea harengus spawning ground. Mar Ecol Prog Ser 174:27-32

Stratoudakis Y, Bernal M, Ganias K, Uriarte A (2006) The daily egg production method (DEPM): recent advances, current applications and future challenges. Fish Fish 7:35-57

Weissburg MJ, Browman HI (2005) Sensory biology: linking the internal and external ecologies of marine organisms. Mar Ecol Prog Ser 287:263-307

Whitehead PJP, Blaxter JHS (1989) Swimbladder form in clupeoid fishes. Zool J Linn Soc 97:299-372

Yamada Y, Okamura A, Tanaka S, Mikawa N and others (2004) Monthly changes in the swim bladder morphology of the female Japanese eel Anguilla japonica in the coastal waters of Mikawa Bay, Japan. Ichthyol Res 51:52-56

> Zwolinski J, Mason E, Oliveira PB, Stratoudakis Y (2006) Fine-scale distribution of sardine (Sardina pilchardus) eggs and adults during a spawning event. J Sea Res 56: 294-304

> Zwolinski J, Morais A, Marques V, Stratoudakis Y, Fernandes PG (2007) Diel variation in the vertical distribution and schooling behaviour of sardine (Sardina pilchardus) off Portugal. ICES J Mar Sci 64:963-972

Appendix 1. Analysis of the relationship between spawning state and swimbladder dynamics in sardine

After analyzing daily egg production method (DEPM) data and showing the spatial segregation of imminent spawners, we hypothesized that bathymetric trends might be related to a possible link between spawning state and swimbladder dynamics. The null hypothesis we tested was that the abrupt ovarian growth at hydration (the gonadosomatic index increases in only a few hours from $5 \%$ at the end of vitellogenesis to $>20 \%$ at late hydration) inside the finite coelomic cavity causes the swimbladder to deflate. This was investigated by analyzing sardine samples collected off Portugal and the Gulf of Cadiz in October 2008 and April 2009 within the remit of autumn and spring acoustic surveys (Table A1). Apart from the standard on-board processing of sardine samples (similar to that reported for the DEPM surveys), sardines were also examined for the dimensional characteristics of their swimbladders through measurement of their ventral cross-section. Specifically, after slitting the abdomen and removing viscera, we carefully opened the coelomic cavity and scored the swimbladders with respect to size (1: small; 2 : medium; 3: large; 4: distended; Fig. A1). Subsequently, specimens were photographed using a camera supported on a vertical plastic stand, with a ruler placed alongside the specimen in order to be able to calibrate scale in subsequent linear measurements. Photographs from a total of 222 sardines were collected (Table A1) and processed with ImageJ (v. 1.43; http://rsbweb.nih.gov/ij/). Ventral crosssectional areas $\left(S B_{\mathrm{xsa}}\right)$ were measured through the perimeter of the swimbladder after calibrating each image using a ruler.
The dichotomous presence/absence of oocyte hydration data were modeled as a function of swimbladder crosssection data in 2 ways. First, the prevalence of hydrated females $\left(P_{\mathrm{h}}\right)$ was compared between the 4 different swimbladder size classes using analysis of means (ANOM) in the Statgraphics Centurion software. The main advantage of this method compared to the use of a chi-squared test for a $2 \times 4$ contingency table is that it allows the determination of a grand mean for the whole set of data as well as lower and upper $95 \%$ decision limits. When $P_{\mathrm{h}}$ in a size class falls outside the decision limits, then it is significantly different from the grand mean. The relationship between the prevalence of hydration and the swimbladder crosssection data was also analyzed by means of a generalized linear model (GLM; binomial error distribution, logit link) using $P_{\mathrm{h}}$ as the predicted variable and the residuals $(R)$ of the power relationship between $S B_{\text {xsa }}$ and body length as the predictor (Fig. $7 \mathrm{~b}$ ). We used $R$ rather than $S B_{\mathrm{xsa}}$ in order to remove the effect of body size from the analysis.

Both the ANOM (Fig. 7a) with the visual staging data and the GLM with the digital-image processing data (Fig. $7 b$ ) showed that the prevalence of ovarian hydration decreased with increasing swimbladder size. In particular, as shown in Fig. $7 \mathrm{a}$, hydrated females mainly possessed swimbladders of small or medium size, while none of the females with distended swimbladder was hydrated. Similarly, the GLM showed a significant relationship between $P_{\mathrm{h}}$ and $R(\mathrm{p}<0.01)$ (Fig. 7b), which further supports our hypothesis of the negative relationship between gonad size at hydration and swimbladder size. 
Table A1. Sardina pilchardus. The 10 samples used to measure swimbladder size. n: number of fish analyzed; L: average body length; $S B_{\mathrm{xsa}}$ : average swimbladder ventral cross-section area. Minimum and maximum values are provided in parentheses

\begin{tabular}{|c|c|c|c|c|c|c|}
\hline Sample & Date $(\mathrm{dd} / \mathrm{mm} / \mathrm{yy})$ & Time (h) & Haul depth (m) & $\mathrm{n}$ & $L(\mathrm{~cm})$ & $S B_{\mathrm{xsa}}\left(\mathrm{cm}^{2}\right)$ \\
\hline 1 & $18 / 10 / 08$ & 09:20 & 25.0 & 29 & $\begin{array}{c}20.1 \\
(18.2-22.2)\end{array}$ & $\begin{array}{c}4.14 \\
(0.70-9.46)\end{array}$ \\
\hline 2 & $19 / 10 / 08$ & $13: 45$ & 17.3 & 39 & $\begin{array}{c}20.3 \\
(19-22.7)\end{array}$ & $\begin{array}{c}5.54 \\
(1.80-12.11)\end{array}$ \\
\hline 3 & $20 / 10 / 08$ & $16: 15$ & 24.0 & 31 & $\begin{array}{c}18.3 \\
(14.7-20.6)\end{array}$ & $\begin{array}{c}2.97 \\
(1.13-5.87)\end{array}$ \\
\hline 4 & $21 / 10 / 08$ & $8: 45$ & 45.5 & 45 & $\begin{array}{c}19.1 \\
(18.0-20.3)\end{array}$ & $\begin{array}{c}3.77 \\
(1.92-7.50)\end{array}$ \\
\hline 5 & $24 / 10 / 08$ & $13: 50$ & 15.0 & 33 & $\begin{array}{c}19.5 \\
(18.5-20.4)\end{array}$ & $\begin{array}{c}4.05 \\
(1.95-7.66)\end{array}$ \\
\hline 6 & $3 / 4 / 09$ & $17: 20$ & 65.0 & 11 & $\begin{array}{c}19.9 \\
(17.5-21.2)\end{array}$ & $\begin{array}{c}3.03 \\
(2.27-4.17)\end{array}$ \\
\hline 7 & $1 / 4 / 09$ & $17: 08$ & 61.0 & 26 & $\begin{array}{c}19.5 \\
(17.6-21.4)\end{array}$ & $\begin{array}{c}2.81 \\
(1.60-4.64)\end{array}$ \\
\hline 8 & 16/4/09 & $15: 57$ & 26.0 & 3 & $\begin{array}{c}18.9 \\
(18.3-19.7)\end{array}$ & $\begin{array}{c}2.28 \\
(1.19-3.36)\end{array}$ \\
\hline 9 & 18/4/09 & $15: 07$ & 49.0 & 3 & $\begin{array}{c}19.4 \\
(19.2-19.7)\end{array}$ & $\begin{array}{c}4.71 \\
(4.45-4.97)\end{array}$ \\
\hline 10 & 21/4/09 & $18: 38$ & 25.0 & 2 & $\begin{array}{c}21.5 \\
(21.2-21.8)\end{array}$ & $\begin{array}{c}5.02 \\
(3.71-6.33)\end{array}$ \\
\hline
\end{tabular}

Fig. A1. Sardina pilchardus. Ventral views of sardines with the abdomen opened to expose swimbladders with (a) small, (b) medium, (c) large, and (d) very large (distended) size. The head is always upwards
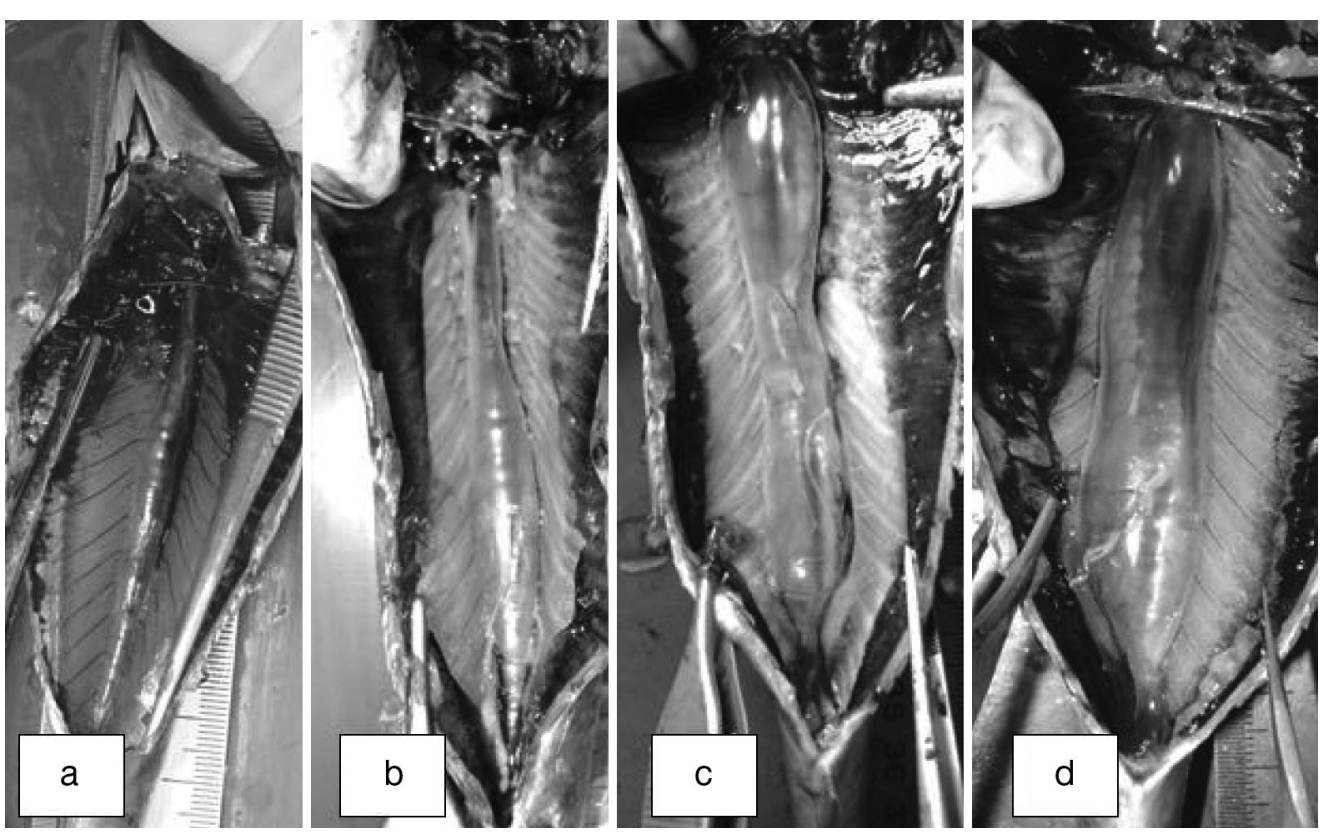

Editorial responsibility: Antonio Bode, A Coruña, Spain
Submitted: November 4, 2010; Accepted: January 29, 2011 Proofs received from author(s): April 11, 2011 